\title{
Customising with 3D printing: The role of intelligent control
}

\begin{abstract}
The emergence of direct digital manufacturing creates new opportunities for the production of highly customised goods especially when it is combined with conventional manufacturing methods. Nevertheless, this combination creates a need for systems that can effectively manage and control the resulting distributed manufacturing process. In this paper, we explore three different configurations that can enable direct digital manufacturing for customisation, ranging from fully integrated to inter-organisational set up. Additionally, control requirements of such systems are developed and the suitability of intelligent control is explored. By 'intelligent control' we mean production control that is capable of assessing and interacting with the production environment and adapting production accordingly. We argue that the so called intelligent product paradigm provides a suitable mechanism for the development of such intelligent control systems. In this approach, the intelligent product directly co-ordinates with design agent, 3D printing agents and other conventional manufacturing system agents to schedule, assign and execute tasks independently. Via a case example of a realistic production system, we propose and implement such an intelligent control system and we analyse its feasibility in supporting 3D printing enabled customisation.
\end{abstract}

Keywords: mass customisation, 3D printing, intelligent control, direct digital manufacturing

\section{Introduction}

Customisation in manufacturing, and especially mass customisation, remains an area of great importance almost three decades after its first appearance [1]. Recent trends in manufacturing has led customisation to attract even greater interest both from the academic community but also from practitioners [2, 3]. Perhaps the most prominent trend — direct digital manufacturing - investigates the utilisation of additive manufacturing technologies, like 3D printing, for local production of customised goods [4. Additive manufacturing technologies, and especially 3D printing, are argued to fall in the category of the advanced manufacturing technologies required for mass customisation [5, 6, due to their special manufacturing capabilities like flexibility and speed [7, 8].

As 3D printing enabled customisation is likely to require the combination or even integration of 3D printing technologies with conventional manufacturing systems, a key question that emerges relates to the planning and control problems associated with this combination/integration 9. Already, since the beginning of the last decade, it has been argued that de-centralised, multi-agent systems are perhaps more suitable to manage these control problems [6] and a recent case study has shown some evidence on this [10. In this study, we aim to further advance our understanding on how intelligent control paradigm can support 3D 
printing enabled customisation. We argue that intelligent control — defined as a production control that is capable of assessing and interacting with the production environment and adapting production accordinglyis a suitable mechanism for managing the order taking, coordination and fulfilment of mass customisation processes [11, while 3D printing contributes primarily on the manufacturing engineering process. Unlike similar studies found in the literature discussing this topic [9, 10, we use a case example of a realistic production system to examine the role of intelligent control in introducing 3D printing resources (or 3D printed parts) in conventional manufacturing systems. The production system under consideration manufactures and assembles customised gear boxes, using a combination of customisable and non-customisable parts.

The contribution of this study is twofold: firstly, it explains and justifies the suitability of intelligent control for 3D printing enabled customisation. Secondly, by developing a realistic production system - along with the associated control system - it demonstrates evidence for the above argument and identifies technical challenges of utilising intelligent control to combine 3D printing with conventional types of manufacturing. The remaining of this paper is structured as follows. In Section 2 we review the role of $3 \mathrm{D}$ printing in mass customisation and we provide a brief review of the intelligent control paradigm. In Section 3, we identify relevant control requirements and we investigate the why and how the intelligent control paradigm addresses these requirements. Section 4 describes the case example used in this study before we conclude with a final discussion in Section 5

\section{Background}

\subsection{Customisation in manufacturing}

\subsubsection{Brief review of mass customisation enablers}

Mass customisation is a generic term used to describe manufacturing customised products for a mass market [1]. It aims to achieve economies of scale and scope that enable customised products to be as affordable as mass produced products [5, 11]. Since its origins, mass customisation was argued to be the answer to an increasing demand for product variety and customisation, while at the same time taking advantage of manufacturing and information technologies that could deliver higher variety at low costs $\underline{6}$. It is out of the scope of this paper to provide a detailed review on mass customisation as there are numerous studies and interested readers can refer to [2] and references therein. Instead we focus on two aspects that have been recognised for their importance in successfully implementing mass customisation: flexible manufacturing systems and information management [5, 6].

Firstly, flexible manufacturing systems act as a mechanism to counterbalance additional costs arising from mass customisation [2]. Utilising "advanced manufacturing technologies", manufacturers can develop flexible and agile manufacturing systems which are required in mass customisation in order to remove barriers to product variety at low cost [].

Secondly, as product variety increases, data becomes unmanageable using classic methods, and alternative approaches to generate Bills of Materials (BOMs) are required [2]. The role of information technologies in 
mass customisation is, therefore, twofold: firstly they can be used to enhance the communication between work teams (product design, manufacturing, supply chain management), thus enabling orders to be fulfilled correctly through the integration of information flows [12]. Secondly, they can improve the interaction with the customer in order to collect customer requirements, demands and preferences during the configuration process [12. In [11, a simple model for the different stages of customisation process is introduced:

- Order taking \& co-ordination

- Product design \& manufacturing engineering

- Order fulfilment management

- Order fulfilment realisation

60

\subsection{2. $3 D$ printing facilitating mass customisation}

3D printing and, more generally, additive manufacturing has been recognised as one of the key technologies enabling customisation mostly due to the high levels of flexibility it can offer [7, 13, 8, 14. There are also arguments found in the literature that 3D printing can significantly revolutionise manufacturing in ways that other mass customisation technologies could not [15].

One of the requirements of mass customisation is rapid product development and innovation capabilities due to typical short life cycles presented by mass customised products [6]. This can be supported by 3D printing, as the technology enables rapid manufacturing which in turn helps design customisation [16, 17. The ability of 3D printing machines to directly utilise 3D models of designed products allows the customer to design his preferences related to products directly [18].

Another key requirement of mass customisation - flexibility of manufacturing systems [2] - is also supported by 3D printing enabled manufacturing as it removes the tooling requirements and thereby allows components of any geometry to be manufactured in a single resource without too much change over time [19. This also means that $3 \mathrm{D}$ printing eliminates the need for having a wide range of tooling and the associated costs. Furthermore, multiple materials can be combined to produce a part, rather than products or parts made of homogeneous materials. Additionally, 3D printing allows for small batch sizes and there is no change over of tools, thus providing flexibility to cater for various customisation requests. Similarly, 3D printing enabled manufacturing offers the possibility of reducing inventory levels of customised parts as some of them can be produced on demand based on actual customer orders.

Due to its speed and flexibility. 3D printing has therefore the potential to impact several mass customisation generic levels [6], from design and fabrication to usage. One could imagine for example a product produced by a manufacturer including parts printed according to specific customer requests (fabrication), which could also be further customised after delivery to satisfy new customer needs (usage). Although a very interesting topic to investigate, a further analysis on the potential impact of $3 \mathrm{D}$ printing on different mass customisation levels/types is out of scope of this study. We simply note here that one of the barriers 
of applying 3D printing in mass production processes, i.e. cost, is argued to decrease significantly over time as adoption levels increase [15].

\subsection{Intelligent control, distribution and customisation}

As discussed earlier, intelligent manufacturing control systems are those that are capable of varying their behaviour in response to dynamic changes, requirements and past experiences 20. Manufacturing operations involve products and resources, and the intelligent control paradigm enables these entities to have the capability to bind the physical object with information and make decisions.

Conventional manufacturing control systems are based on centralised and hierarchical units that are not well suited for handling high product variety, support customisation and have weak response to disruptions 21. Intelligent, distributed control systems, on the other hand, provide new pathways to overcome the challenges of centralised control systems. These systems have distributed units interacting with each other and collaboratively making control decisions [22].

These collaborative control systems are generally based on multi-agent and holonic manufacturing paradigms [23, where the individual products, manufacturing resources and other key functions are represented as units capable of decision making, information processing and communication. These systems have the ability to support small batches and high product variety due to their ability to adapt, communicate and learn.

One of the central themes behind these intelligent control systems is the ability to identify unique products and resources physically, and map these to software agents that can pass information, process them and make decisions. The developments in auto-id technologies provide capabilities for identifying products and resources [20]. This has then led to the notion of product-driven intelligent control and the intelligentproduct paradigm, where a physical order or product instance can guide or govern the way it is intended to be made by negotiating with the resources 24 . Such approaches are well suited for customisation scenarios by eliminating the need to have fixed process plans and routing $[9,25,26$. In the following section we will explore the ability of such product-driven intelligent control systems to perform 3D printing enabled customisation.

\section{Intelligent control supported customisation via 3D printing}

\subsection{Using 3D printing resources in conventional manufacturing processes}

We identify three key configurations that allow the usage of 3D printing resources in manufacturing depending upon the location of the flexible resource and its integration in conventional manufacturing processes. It is important to look at the value chain in our analysis as in practice there might not be a single point of customisation, i.e. a customised product can have some features that involve customised fabrication and other features that require customised assembly [11]. These different configurations will require different coordination capabilities to control and manage customisation requests. The configurations are depicted in Figure 1. 


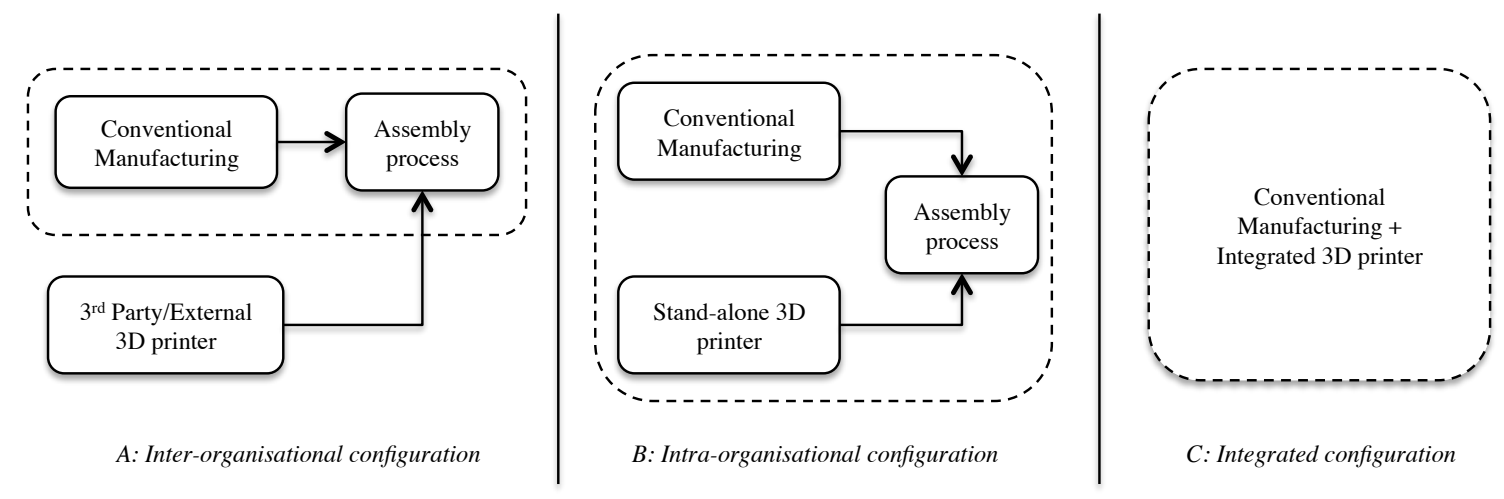

Figure 1: Configurations for the usage of 3D printing in manufacturing

Configuration A (inter-organisational) describes a configuration in which 3D-printed parts and compo-

\subsection{Control requirements for 3D printing-enabled customisation}

Implementing Configuration B creates requirements for integrated order management and control [6]. The control requirements in this configuration are significant, however, and we list these in Table 1 (2nd 
column), grouping them per mass customisation process, following the model proposed in [11.

Table 1: Control requirements and capabilities for customisation using 3D printing

\begin{tabular}{|c|c|c|}
\hline $\begin{array}{l}\text { Mass customisation } \\
\text { processes 11] }\end{array}$ & $\begin{array}{l}\text { Control requirements for } 3 \mathrm{D} \text { Printing customisa- } \\
\text { tion }\end{array}$ & Intelligent control capabilities needed to address requirements \\
\hline $\begin{array}{l}\text { Order taking \& co- } \\
\text { ordination }\end{array}$ & $\begin{array}{l}\text { - Manage small batch size and handle orders ar- } \\
\text { riving at random intervals with varying due- } \\
\text { dates } \\
\text { - Manage products/orders, BOM, production } \\
\text { recipe uniquely } \\
\text { - Tracking/status management of orders and } \\
\text { parts in real-time across the value chain } \\
\text { - Share information regarding disruptions, re- } \\
\text { solve conflicts and allocation changes dynam- } \\
\text { ically }\end{array}$ & $\begin{array}{l}\text { - Adaptable production planning and control in real time for } \\
\text { - dynamically changing environments } \\
\text { lows control of manufacturing routes depending upon cus- } \\
\text { tomisation requirements } \\
\text { - Product-driven intelligent systems can autonomously decide } \\
\text { on production plans and can track its own status continuously } \\
\text { - Distributed production and order entities can pass informa- } \\
\text { tion and negotiate to resolve conflicts using, for example, } \\
\text { market based techniques such as auctions }\end{array}$ \\
\hline $\begin{array}{l}\text { Product design \& } \\
\text { manufacturing en- } \\
\text { gineering }\end{array}$ & $\begin{array}{l}\text { - Ability to quickly convert design changes into } \\
\text { direct manufacturing capabilities } \\
\text { - Dynamically assess manufacturability of design } \\
\text { changes } \\
\text { - Handle varying levels of customer involvement }\end{array}$ & $\begin{array}{l}\text { - Products can autonomously verify whether designs are in } \\
\text { compliance with standards } \\
\text { - Automatic verification of manufacturability and the system } \\
\text { need to understand design parameter changes and its associ- } \\
\text { ated production process impact } \\
\text { - Learning optimal production parameter setting for each de- } \\
\text { sign instances }\end{array}$ \\
\hline $\begin{array}{l}\text { Order fulfilment } \\
\text { management }\end{array}$ & $\begin{array}{l}\text { - Coordinate/control production process re- } \\
\text { quests across multiple organisations } \\
\text { - Dynamically schedule production plans as or- } \\
\text { ders arrive (inter and intra company) } \\
\text { - Reschedule or alter schedule to manage dis- } \\
\text { ruptions (e.g. late customisation, due-date } \\
\text { changes) } \\
\text { - Batch orders/processes to reduce set-up/ } \\
\text { change over times }\end{array}$ & $\begin{array}{l}\text { - Autonomous agents represents products and resource entities } \\
\text { both within and external to organisations to negotiate and } \\
\text { schedule operations. } \\
\text { - Supervisory, facilitator or mediation agents will allow over- } \\
\text { seeing of operations across multiple business units or across } \\
\text { organisations. } \\
\text { - Reschedule or alter schedule to manage disruptions (e.g. late } \\
\text { customisation, due-date changes) }\end{array}$ \\
\hline $\begin{array}{l}\text { Order fulfilment re- } \\
\text { alisation }\end{array}$ & $\begin{array}{l}\text { - Should be able to change process routes by } \\
\text { utilising the underlying system and/or process } \\
\text { flexibility } \\
\text { - Directly send customisation manufacturing re- } \\
\text { quirements to resources on demand }\end{array}$ & $\begin{array}{l}\text { - Product driven control and distributed scheduling ensures } \\
\text { correct execution of transport and transformation operations } \\
\text { - Order agents are associated with design files which can be } \\
\text { directly sent to 3D printer for customisation. } \\
\text { - Agents associated with 3D printing can update the status of } \\
\text { operation to order agents for state tracking. }\end{array}$ \\
\hline
\end{tabular}

It is apparent from the middle column in Table 1 that control systems for mass customisation are required to be able to handle increased complexity, offer greater flexibility and enhance disruptions management. 
Conventional, centralised control systems are therefore not suitable for mass customisation systems and it has been argued that decentralised, multi-agent control systems could be used instead 6, 10, 9]. Therefore, in the third column of Table 1 we describe the role of intelligent control and the different ways it can support each mass customisation process thus arguing about its suitability in more detail.

\subsection{Application of Intelligent control for 3D printing enabled customisation}

The challenges in adapting manufacturing systems to cope with customisation requires production planning and control functions that are self adapting and self coordinating. For this purpose, in this section, we propose an intelligent control based approach for handling customisation in which the order to be made drives the distributed production resources. Figure 2 illustrates the proposed concept, which is based on the intelligent product approach described in section 2.2 .

A necessary prerequisite for handling customisation is the provision, administration and management of essential product-related data. Products encapsulate all customisation-related information along with additional information such as quality tolerances. This information is continuously updated to track the status of the product. Figure 2 illustrates the various collaborations that takes places between the intelligent product and other entities in the system to realise efficient customisation.

1. Order taking \& coordination: For order taking and coordination an order is associated with each customer's individual requests and their due dates. The intelligent product is then instantiated to include BOM and unique recipes. This intelligent product constantly updates the status of order progression to the customer, thus enabling full visibility to the customer of the status of the manufacturing process. In a mass customisation scenario each product is unique and is associated with individual customisation requests. Depending on the context, this can range from full bespoke product to standard customisation options.

2. Product design and manufacturing engineering: The intelligent product then liaises with design center to develop CAD drawings and associated BOMs. The use of direct manufacturing technology enables easy assessment of manufacturability and design changes. Additionally, the design centers can liaise with the customers to carry out design iterations to satisfy individual needs.

3. Order fulfilment management:Once the product design has been decided, order fulfilment management is carried out by distributed scheduling and negotiation by the intelligent product with customisation resource. Products use a type of resource directory to determine the available resources and their capabilities. The product then uses contract net protocol to select bids from the customisation resources. The selection includes the cost of customisation and the ability to meet the due date. The product then reserves the operation with customisation resource and sends the design file obtained from the design center. 


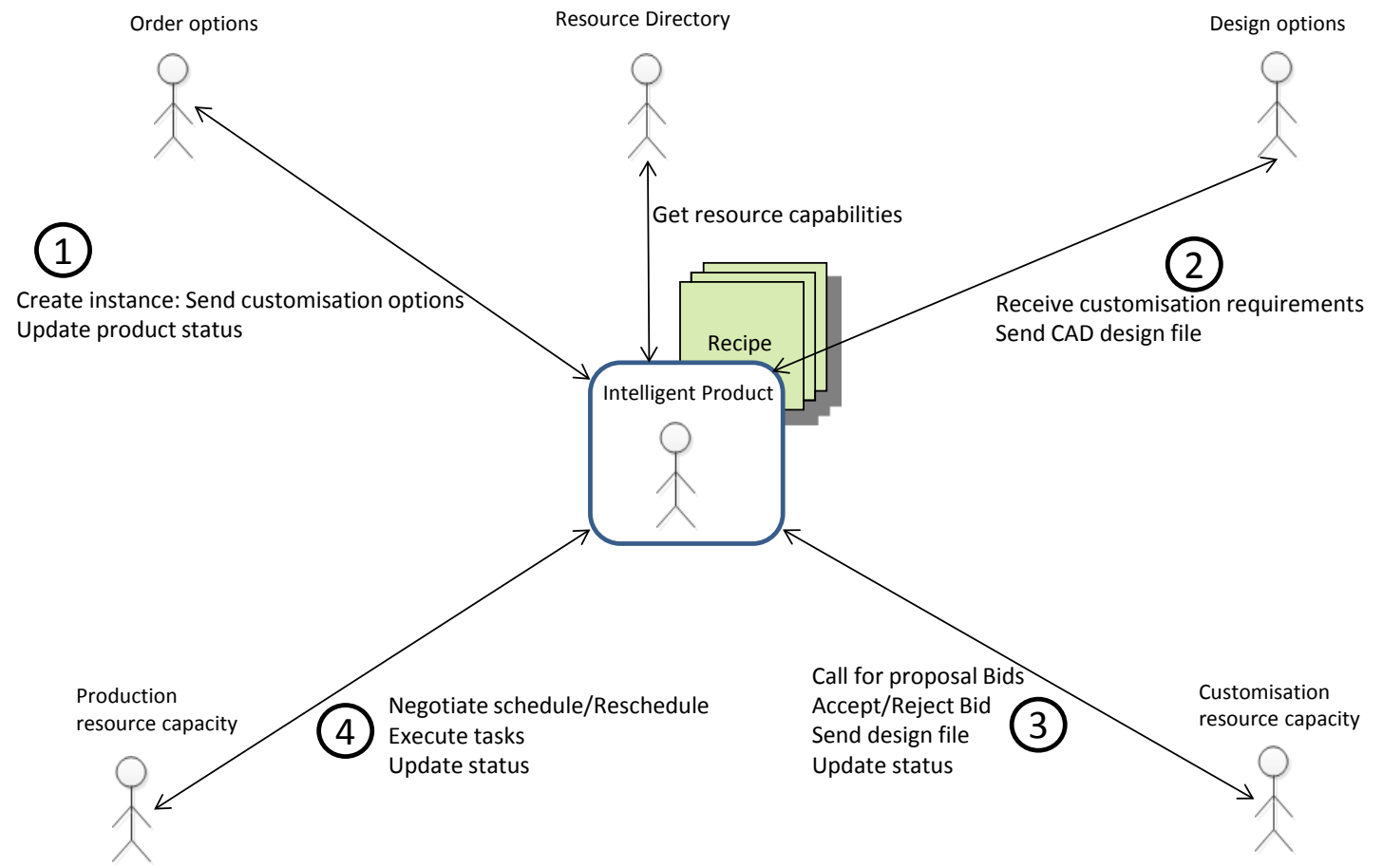

Figure 2: Product driven control for customisation using 3D Printing

4. Order fulfilment realisation: Intelligent product co-ordinates with transportation agents and resource agents to execute the tasks to realise the completion of production operations. Any late customisation changes are easily accommodated by re-negotiating with the customisation resource.

The use of 3D printers provides additional capabilities such as no tooling and direct digital manufacturing. However, from a control perspective, this requires additional planning and scheduling. With highly customised products, the build time varies between different printer types and material used, thereby making planning and scheduling more complex. Additionally, when 3D printing fails during the build, there needs to be a way to detect this failure. The control system needs to have a mechanism to determine or predict print failures, so the task can be rescheduled quickly. We expect the application of intelligent control will provide quick re-organisation of tasks during failure. In order to validate that the approach in Figure 2 is actually practical and feasible, we implemented it as a part of a laboratory based case study.

\section{Case study: customised gear box manufacturing}

In this section we use a case example of gear box component production and assembly to examine in more detail the role of intelligent control in mass customisation production systems using 3D printing. Our case example describes customisation at the assembler and manufacturer decoupling point 2 .

We examine this case example from two perspectives often used to describe mass customisation systems [5. Firstly (Section 4.1), we study the nature of customisation required and the customer's involvement so 
that we can distinguish customisation from variety [5]. Secondly (Sections 4.2 4.3), we analyse the necessary means for achieving customisation and the way the required intelligent control systems were developed and implemented. The evaluation of the case example and the extent to which the appproach is validated in this instance are described in Section 4.4

\subsection{Product and customisation options}

A gear box is used as an example product and is depicted in Figure 3 . The gear box consists of both non-customisable and customisable parts. There are three non-customisable parts in a gear box, i.e. a metal casting (top and bottom), a plastic cover and screws. There are also two customisable parts, enabling different types of customisation:

1. Gears: There are two gears in each gear box. The ratios of the gears can be decided and modified by the customers. By allowing a customer to alter the ratios according to their needs and preferences, he is allowed to customise the functionality of the gear box 1 .

2. Cap: A coloured cap can be added to the gear box, fitting on top of the plastic cover. A customer can choose the colour of the cap as well as design the text and/or logo appearing on it. This is a primarily a cosmetic product customisation with more design freedom given to the customer.

The two customisable parts enable a varying degree of customisation from complimentary, aesthetic changes (cap) to changes modifying the functional working of the product (gears). In both options, customers can design their own parts or can specify their requirements to a designer.

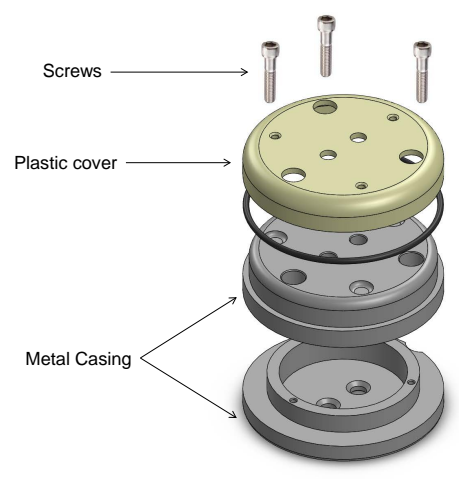

(a) Bill of materials

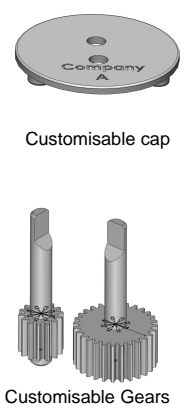

Customisable Gears

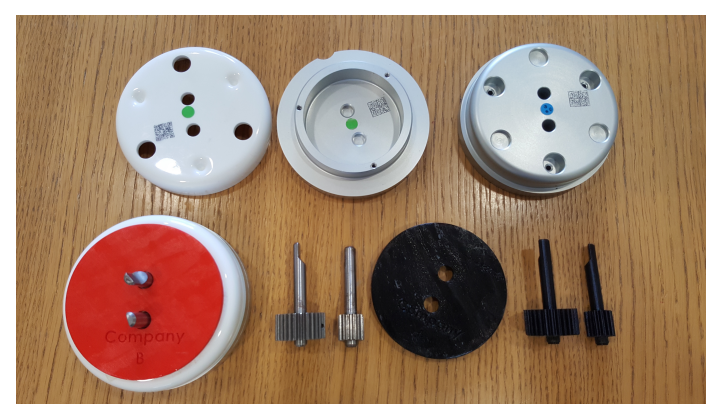

(b) Gear box manufactured parts

Figure 3: Gear box

\subsection{Production system description}

Figure 4 illustrates the production system, which consists of three manufacturing cells. Cell 1 is the manufacturing cell where the metal casing is machined and the plastic cover is vacuum formed. At this

\footnotetext{
${ }^{1}$ A short video demonstrating the printing process of the gears can be found at $<$ url removed for double-blind review $>$
} 
stage, each of these parts are uniquely marked using an inkjet printer. Cell 2 is the sub-assembly cell which assembles the plastic cover with the metal top. Cell 3 is the final assembly cell where all parts are put

\footnotetext{
${ }^{2} \mathrm{~A}$ short video demonstrating the assembly of the gear box using 3D-printed gears can be found at <url removed for double-blind review $>$
} 


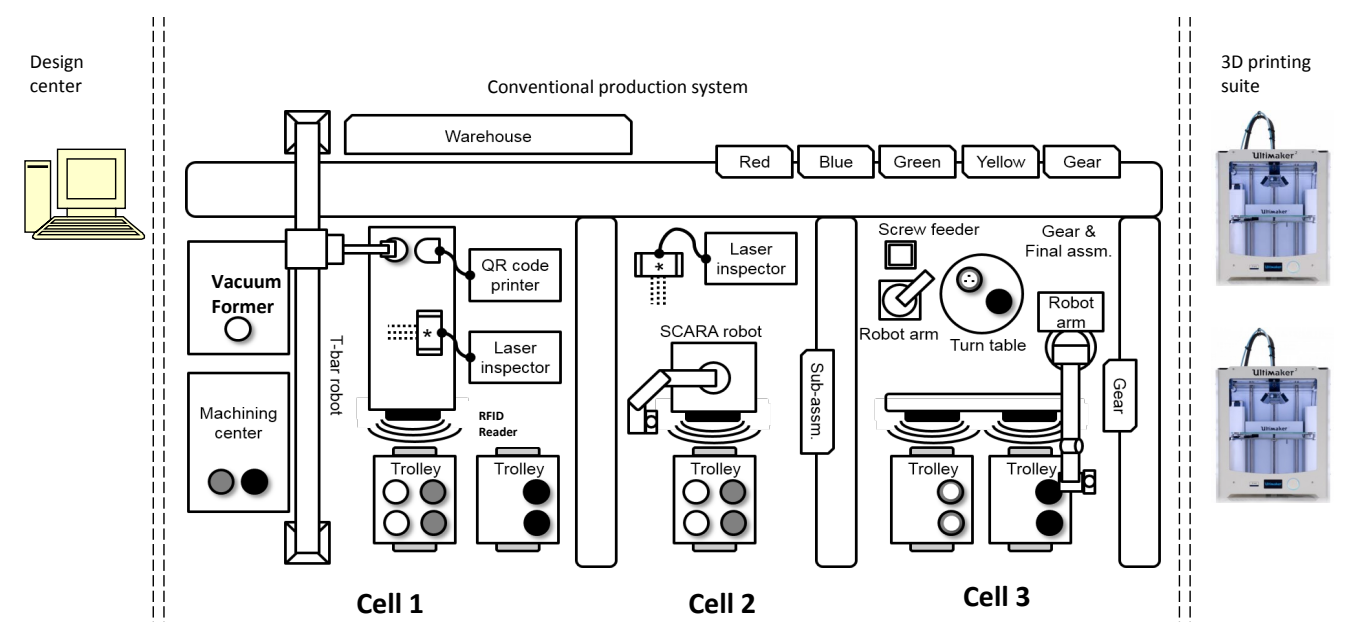

(a) Layout

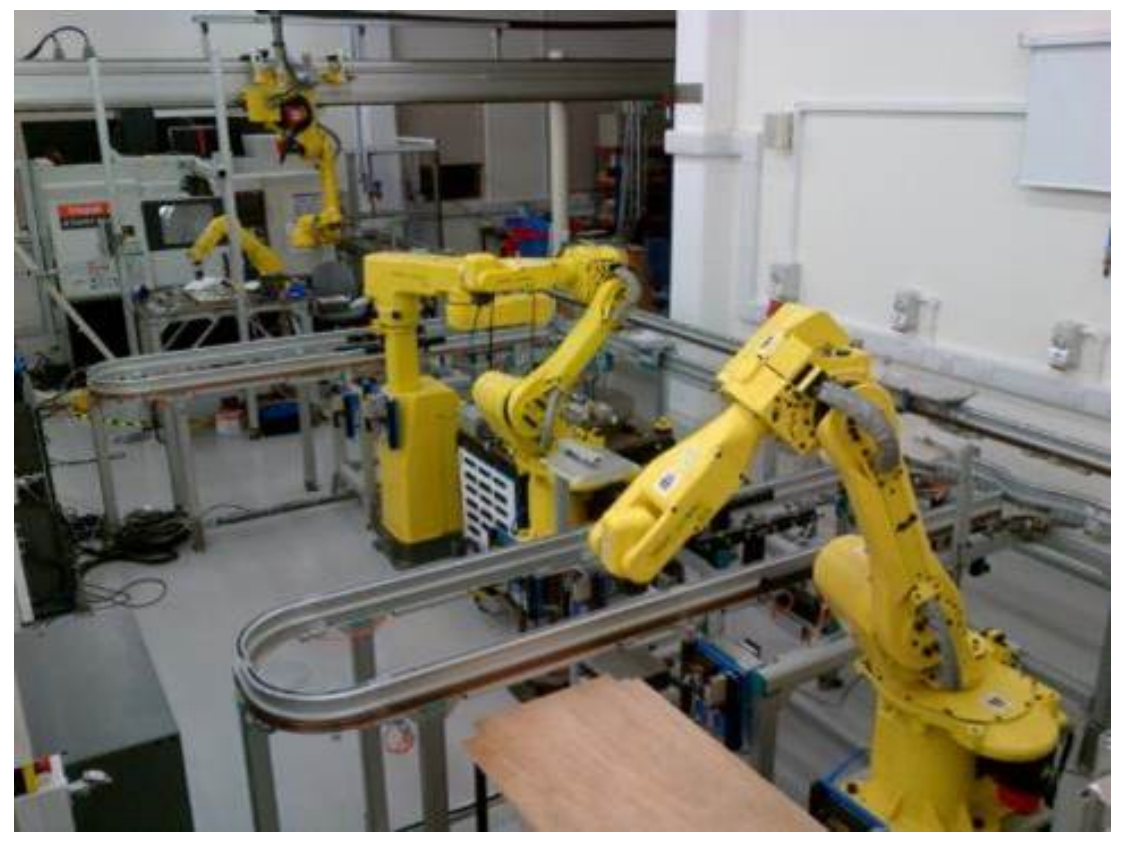

(b) Gear box manufactured parts

Figure 4: Production System 
The agents selected were based around the decisions needing to be made within the control environment. Additionally, there is the information infrastructure that allows the agents to communicate and pass information. This infrastructure can range from a simple black-board type agent communication to complex message passing based on FIPA communication standards. The agent architecture is illustrated in Figure 5.

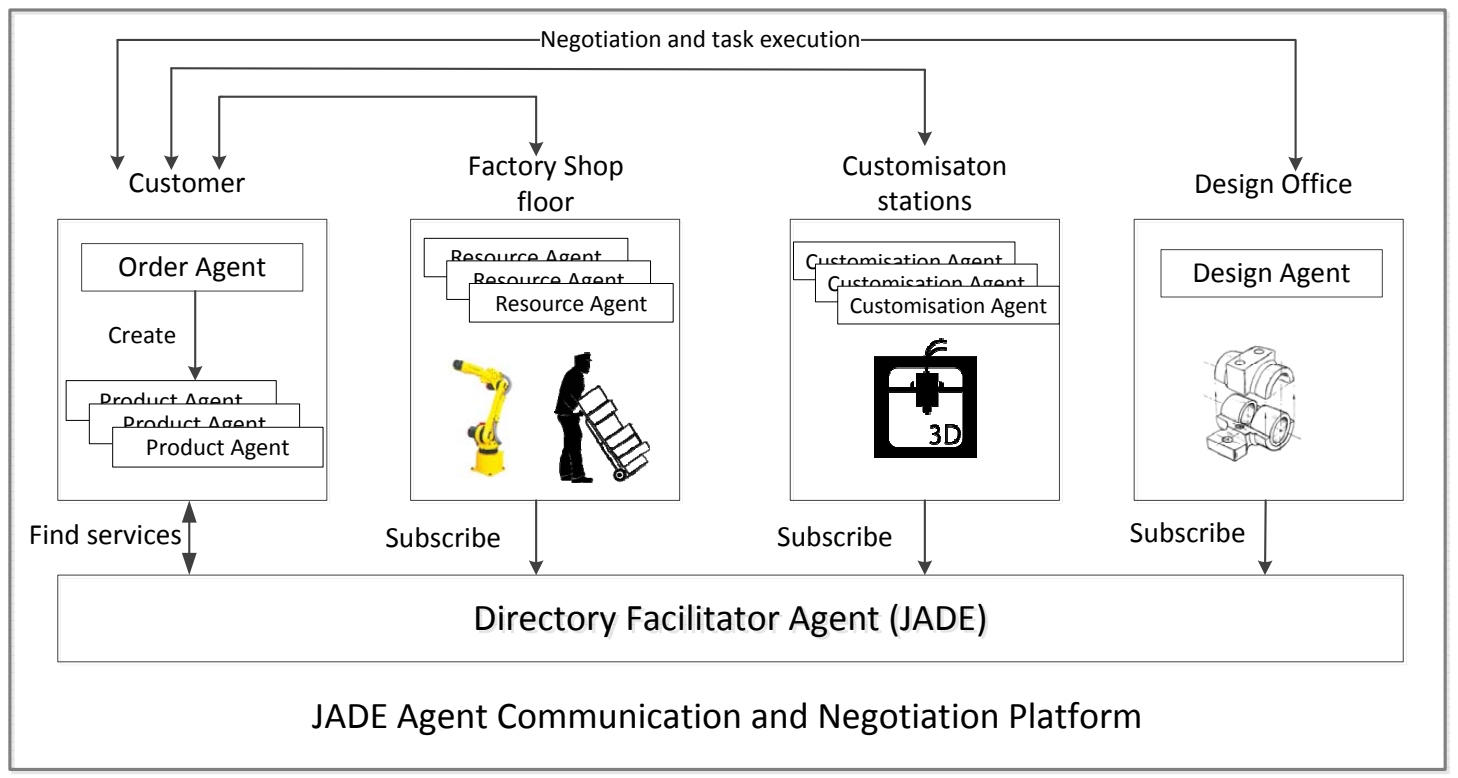

Figure 5: Intelligent control configuration for customisation using 3D Printing

Figure 6 shows the implementation of the intelligent control system. In order to maintain low latency and fault recovery, the conventional production system is controlled by PLCs and communicates with conventional manufacturing resources using device net. An OPC server is then used as a blackboard mechanism for agents to interact between virtual agents and the physical objects (such as robots, conveyors). However, one of the main challenges was to incorporate the customisation agent within the 3D printers, as it did not have options for information processing and communication. To overcome this challenge, a Raspberry Pi computer was added into the 3D printers which acted as a HTTP server and accommodated the agents. This set up allowed the agents to transfer the design file automatically, monitor the progress of the operations and start customisation operations. This enabled the customisation agents to carry out operations with less manual intervention.

In order to uniquely identify parts, a data matrix is printed on to the metal top and base, and the plastic cover. Additionally, RFID system is employed to track materials and resources in the production line. Furthermore, trolleys equipped with RFID are used to move gears and cap (customised parts) between the 3D printers and conventional manufacturing cells. These two uses of RFID combined with data matrix information allow the product agents to update the status and location in real time. The intelligent product agent then uses this information to dynamically coordinate tasks with other resources. For instance, the 


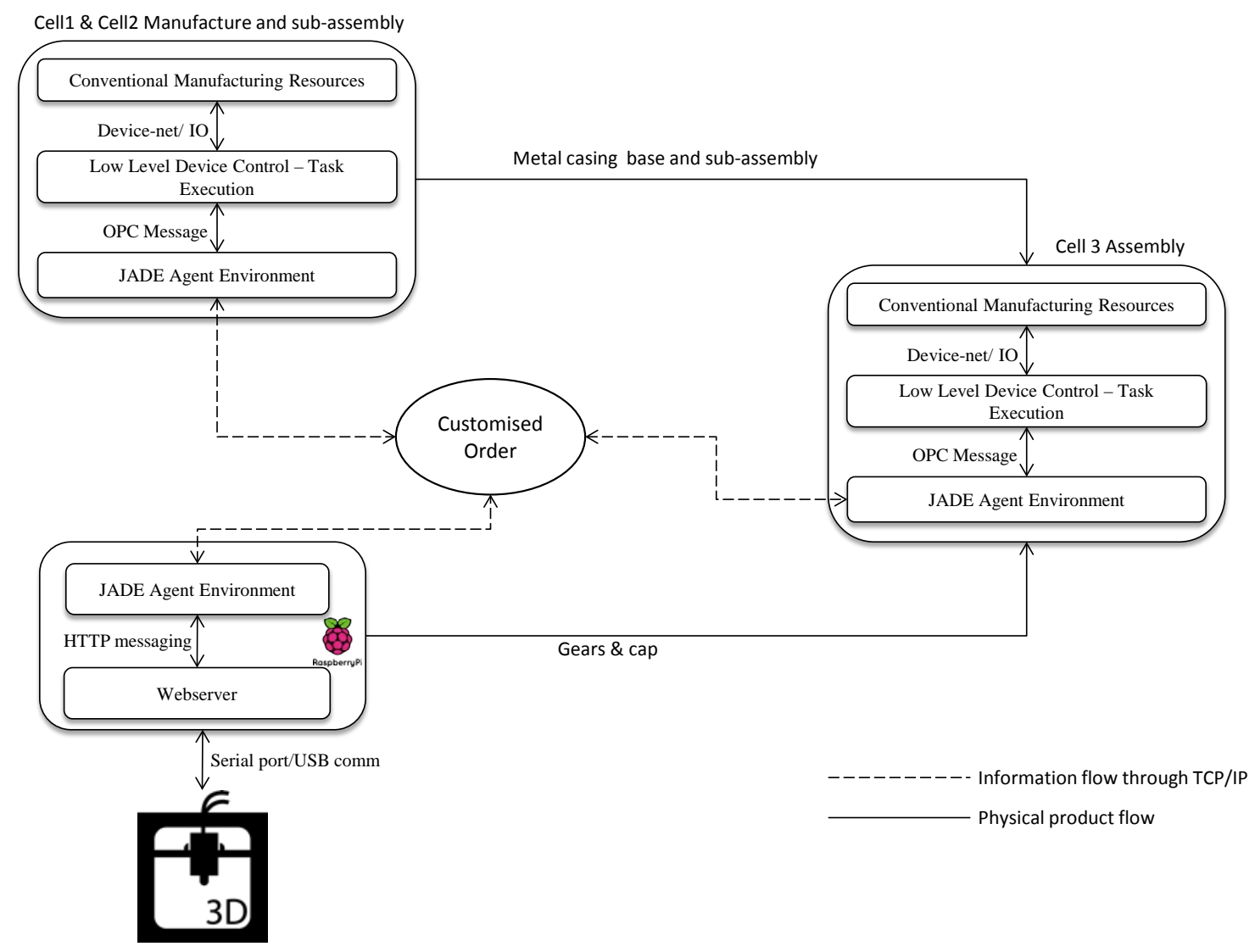

Figure 6: System architecture implementation used in the case study

product agent can get a predicted time for manufacture, which it then uses to schedule other assembly resources with less delay. As 3D printing is a time consuming process, the product agent first negotiates with the printer agent regarding the start and finish time of the requested print job. This is then used by the order agent as a due date to schedule the remaining assembly process with other resources. In the following subsection, we evaluate the performance of the implementation and discuss the challenges.

\subsection{Evaluation and validation of the approach}

Ninety six gear boxes were produced in an experiment before evaluating the intelligent control approach and in order to identify key technical challenges. The production of a single gear box from beginning to end took on average $30 \pm 5$ minutes. A gear box spent on average 20 minutes in Cell 1, 3 minutes in Cell 2 and 5 minutes in Cell 3 with total transportation time between cells around 2 mins. Printing a pair of gears required approximately 25 minutes and a cap around 10 minutes.

We first evaluate the implementation of the intelligent control approach to effectively address the challenges in manufacturing customised products using the key requirements in Table 1 .

- Order taking and coordination: Product agents, encapsulated with design and manufacturing in- 
formation, are identified uniquely with ID technologies, and drive the production process and achieve customisation. Moreover, product agents coordinate with design and customisation agents to autonomously decide production plans.

- Product design and manufacturing engineering: Product agents are embedded with techniques that automatically check for design compliance. 3D printers provide efficient mechanisms for customising products as they require no tooling or set up changes between products. Additionally, 3D printers associated with customisation agents enabled direct transfer and conversion of design files and was able to print both customisation options (gears and cap) within the same resource. The 3D printers were enhanced with intelligence by adding a small computer (raspberry pi) and this allowed customisation agents to monitor the printing progress. Additionally, temperature data from print bed and hotends of $3 \mathrm{D}$ printers are stored for each job and in the future this can allow agents to learn optimal parameter setting based on product features.

- Order fulfilment and management : Distributed scheduling based on contract net protocol facilitate the intelligent product agent to coordinate the assembly operation based on the schedule of 3D printers. In the event of a disruption such as quality problems or printer failures, the product agent was able to re-negotiate and re-schedule operations autonomously. The use of yellow-page agents allowed easy addition and removal of customisation agents. This allowed new 3D printers to be added or removed with ease depending on the demand of products.

- Order fulfilment realisation: RFID and data matrices are embedded with the product and the material movement resources allowed product agents to continuously monitor the state and status of production. This allows flexible routing and alternate process plan as the virtual agents are updated with physical location and status in real time. Additionally, the visibility offered by tracking enabled the system to automatically handle rush order or any late customisation changes with ease.

We further identified five key technical challenges for the integration of 3D printers into an intelligent control system:

- Limited communication: Existing 3D printers use different communication interfaces (e.g., Ethernet, serial ports) thus making standardisation challenging. Furthermore, most 3D printers are not interoperable with standard manufacturing devices (e.g. PLC).

- Inconsistent information interfaces: There is limited monitoring of control interfaces and task execution in $3 \mathrm{D}$ printers. The ability to control and communicate with $3 \mathrm{D}$ printers varies between manufacturers (open source vs. proprietary tools). Furthermore, the conversion of CAD files into machine codes is not standardized.

- Response latency : Mass customisation requires different production recipes for each product and 3D printers need support structure for printing those products. However, this implies that build time 
estimates are time consuming and varies, and when there are multiple 3D printers involved, distributed scheduling of tasks takes time. Agents have to wait for responses from different $3 \mathrm{D}$ printers with respect to job time and build estimate time.

- Limited quality control capability: Additive manufacturing is relatively new technology and lacks understanding of quality issues. Moreover, in-process sensing of the quality of 3D printed parts is not well developed.

- Complex (automated) material handling: The ability to automatically transfer materials in and out of a 3D printer is limited with today's robot systems. Moreover, additive manufactured parts can sometimes vary in tolerances and can create additional challenges for material handling robots to pick, place and assembly operations. Flexible end-effectors with variable tolerances were used to overcome this challenge.

The case study has therefore provided a limited validation of the intelligent product-driven control of a 3D printer integration. With some minor extensions to typical resource agents (e.g customisation agents to manage customisation), the approach has been found to work effectively in this production situation. We note that it was beyond the scope of the study to validate the system in terms of performance.

\section{Conclusions}

The emergence of direct digital manufacturing creates new opportunities for manufacturers to offer innovative customisation options, potentially at a mass level. Combining direct digital manufacturing and conventional manufacturing technologies to enable mass customisation creates the need to effectively plan and control the resulting manufacturing process. In this study, we examined how the intelligent control paradigm can provide the necessary capabilities to handle 3D printing enabled customisation. The implementation in a realistic production system allowed the evaluation of the feasibility of the intelligent control approach and highlighted the key technical limitations of the overall system.

Our study indicates that extending a distributed control approach to include 3D printers was logically straightforward, as most 3D printers are stand-alone machines. This provides limited support for validity of intelligent control as a suitable approach for managing high levels of customisation associated with 3D printing integration. However, our experiments highlighted the hardware issues for processing and controlling the 3D printers as well as for allowing agents to run on 3D printers independently. A viable enabled for the interaction between software agents and 3D printers could be small, single board computers (like the Raspberry Pi that was used here). However, there still remains the challenge of interface standardisation and converting $3 \mathrm{D}$ models into g-codes for execution.

As the advent of $3 \mathrm{D}$ printing allows manufacturers to offer customisation at various stages in the value chain, we believe that the proposed agent-based control approach — being modular and scalable - can be 
easily modified or extended to enable other possible configurations not examined in this study. A further new line of research would therefore be the evaluation of the intelligent control approach for inter-organisational or integrated manufacturing systems.

From the perspective of the intelligent control community, this is perhaps one of the few studies that implements an intelligent control approach in a realistic production system and demonstrated its feasibility and associated challenges. We expect further research utilising similar implementations will contribute towards the adoption of this control paradigm in industrial applications.

\section{References}

[1] S. M. Davis, Future perfect, Addison-Wesley Publishing, Reading, MA, 1987.

口 [2] F. S. Fogliatto, G. J. da Silveira, D. Borenstein, The mass customization decade: An updated review of the literature, International Journal of Production Economics 138 (1) (2012) 14-25. doi:10.1016/ j.ijpe.2012.03.002

URL http://www.sciencedirect.com/science/article/pii/S0925527312000989

[3] H. Pearson, G. Noble, J. Hawkins, EPSRC and ESRC redistributed manufacturn ing workshop report, Available online at https://www.epsrc.ac.uk/newsevents/pubs/ re-distributed-manufacturing-workshop-report/. Accessed May 2017 (2013).

[4] D. Chen, S. Heyer, S. Ibbotson, K. Salonitis, J. G. Steingrimsson, S. Thiede, Direct digital manufacturing: definition, evolution, and sustainability implications, Journal of Cleaner Production 107 (Supplement C) (2015) 615-625. doi:10.1016/j.jclepro.2015.05.009

URL http://www.sciencedirect.com/science/article/pii/S0959652615005429

[5] R. Duray, P. T. Ward, G. W. Milligan, W. L. Berry, Approaches to mass customization: configurations and empirical validation, Journal of Operations Management 18 (6) (2000) 605-625. doi:10.1016/ S0272-6963(00) 00043-7.

URL http://www.sciencedirect.com/science/article/pii/S0272696300000437

[6] G. Da Silveira, D. Borenstein, F. S. Fogliatto, Mass customization: Literature review and research directions, International journal of production economics 72 (1) (2001) 1-13.

[7] D. Eyers, K. Dotchev, Technology review for mass customisation using rapid manufacturing, Assembly Automation 30 (1) (2010) 39-46.

URL https : //search.proquest . com/docview/212598915?accountid=9851

[8] D. Deradjat, T. Minshall, Implementation of rapid manufacturing for mass customisation, Journal of Manufacturing Technology Managementdoi:10.17863/CAM.4528. 
[9] J. Holmström, M. Holweg, S. H. Khajavi, J. Partanen, The direct digital manufacturing (r)evolution: definition of a research agenda, Operations Management Research 9 (1) (2016) 1-10. doi:10.1007/ s12063-016-0106-z.

URL http://dx.doi.org/10.1007/s12063-016-0106-z

385

[12] A. J. Dietrich, S. Kirn, V. Sugumaran, A service-oriented architecture for mass customization - a shoe

[13] S. H. Khajavi, J. Partanen, J. Holmström, Additive manufacturing in the spare parts supply chain,

[10] J. Lyly-Yrjninen, J. Holmstrm, M. I. Johansson, P. Suomala, Effects of combining product-centric control and direct digital manufacturing: The case of preparing customized hose assembly kits, Computers in Industry 82 (2016) 82-94. doi:10.1016/j.compind.2016.05.009. URL http://www.sciencedirect.com/science/article/pii/S0166361516300914

[11] B. MacCarthy, P. G. Brabazon, J. Bramham, Fundamental modes of operation for mass customization, International Journal of Production Economics 85 (3) (2003) 289-304.

industry case study, IEEE Transactions on Engineering Management 54 (1) (2007) 190-204. doi: 10.1109/TEM. 2006.889076.

Computers in Industry 65 (1) (2014) 50-63. doi:10.1016/j.compind.2013.07.008

URL http://www.sciencedirect.com/science/article/pii/S0166361513001565

[14] A. Sasson, J. C. Johnson, The 3D printing order: variability, supercenters and supply chain reconfigurations, International Journal of Physical Distribution \& Logistics Management 46 (1) (2016) 82-94. doi:10.1108/IJPDLM-10-2015-0257.

URL http://dx.doi .org/10.1108/IJPDLM-10-2015-0257

[15] B. Berman, 3-d printing: The new industrial revolution, Business Horizons 55 (2) (2012) 155-162. doi:10.1016/j.bushor.2011.11.003. URL http://www.sciencedirect.com/science/article/pii/S0007681311001790

[16] N. Hopkinson, R. Hague, P. Dickens, Rapid manufacturing: an industrial revolution for the digital age, John Wiley \& Sons, 2006.

[17] J. Holmstrm, J. Partanen, J. Tuomi, M. Walter, Rapid manufacturing in the spare parts supply chain: Alternative approaches to capacity deployment, Journal of Manufacturing Technology Management 21 (6) (2010) 687-697. doi:10.1108/17410381011063996.

URL http://dx.doi.org/10.1108/17410381011063996

[18] R. Hague, I. Campbell, P. Dickens, Implications on design of rapid manufacturing, Proceedings of the Institution of Mechanical Engineers, Part C: Journal of Mechanical Engineering Science 217 (1) (2003) 25-30. doi:10.1243/095440603762554587. 
[19] C. J. Tuck, R. J. M. Hague, M. Ruffo, M. Ransley, P. Adams, Rapid manufacturing facilitated customization, International Journal of Computer Integrated Manufacturing 21 (3) (2008) 245-258.

[20] D. McFarlane, S. Sarma, J. L. Chirna, C. Wong, K. Ashton, Auto id systems and intelligent manufacturing control, Engineering Applications of Artificial Intelligence 16 (2003) 365-376.

[21] P. Leitao, Agent-based distributed manufacturing control: A state-of-art survey, Engineering applications of artificial intelligence 22 (2009) 979-991.

[25] J. Barbosa, P. Leitao, E. Adam, D. Trentesaux, Dynamic self-organization in holonic multi-agent n manufacturing systems: The ADACOR evolution, Computers in Industry 66 (2015) 99-111. doi: 10.1016/j.compind.2014.10.011.

[26] C. Wong, D. McFarlane, A. Zaharudin, V. Agarwal, The intelligent product driven supply chain, in: 2002 IEEE International Conference on Systems, Man and Cybernetics, Vol. 4, IEEE, 2002, p. 6.

[27] S. Ford, T. Minshall, Defining the research agenda for 3D printing-enabled re-distributed manufacturing, in: S. Umeda, M. Nakano, H. Mizuyama, H. Hibino, D. Kiritsis, G. von Cieminski (Eds.), Advances in

http://wWw.sciencedirect.com/science/article/B6V2D-47C8VP3-1/2/ f752443c72581005b1ff8a15ffe75618

427-432. doi:10.1016/S0007-8506(07)60137-1.

URL http://www.sciencedirect.com/science/article/pii/S0007850607601371

[24] D. McFarlane, V. Giannikas, A. C. Wong, M. Harrison, Product intelligence in industrial control: Theory

口 and practice, Annual Reviews in Control 37 (1) (2013) 69-88. doi:10.1016/j.arcontrol.2013.03. 003.

URL http://www.sciencedirect.com/science/article/pii/S1367578813000059 Production Management Systems: Innovative Production Management Towards Sustainable Growth, Springer International Publishing, 2015, pp. 156-164. doi:10.1007/978-3-319-22759-7\_18.

[28] S. Prendeville, G. Hartung, E. Purvis, C. Brass, A. Hall, Makespaces: From Redistributed Manufacturing to a Circular Economy, Springer International Publishing, Cham, 2016, pp. 577-588. doi:10.1007/978-3-319-32098-4_49.

URL http://dx.doi .org/10.1007/978-3-319-32098-4_49 
[29] D. Furness, Meet project skywalker: A fully-automated 3D printing factory operated by a robotic arm, Digital Trends. Available online at https://www.digitaltrends.com/cool-tech/ voodoo-skywalker/. Accessed August 2017. 